\title{
ACIDENTES GRAVES DO TRABALHO NA CAPITAL DO ESTADO DE SÃO PAULO (BRASIL)
}

Diogo Pupo Nogueira* Jorge da Rocha Gomes * Naim Sawaia ** NogueIRA, D. P. et al Acidentes graves do trabalho na Capital do Estado de São
Paulo (Brasil). Rev. Saíde públ., S. Paulo, 15-3-13, 1981.

RESUMO: Em 1970, o Grupamento de Acidentes do Trabalho (GAT) do INPS desenvolveu programa preventivo contra os acidentes de trabalho. Detalhes operacionais deste programa são descritos, e o resultado da investigação de 3.930 acidentes graves é analisado. Estes acidentes foram estudados quanto às seguintes variáveis: estado civil, faixa etária, sexo, profissão, tipo, consequiências, fatores, dia da semana, hora do dia, horas decorridas do início do serviço, causas e número de lesões. prevenção.

UNITERMOS: Acidentes do trabalho, São Paulo, SP, Brasil. Acidentes,

\section{N T R O D U Ç A O}

A política de prevenção de acidentes do trabalho vem atravessando uma fase de mudanças contínuas. Saad 9 , ao escrever sobre política social, traça um histórico desta evolução, a partir de 1930 até a atualidade, onde se verifica a constante preocupação com as leis que protegem o trabalhador. Ferreira ${ }^{3}$ refere que em 1973, o então Instituto Nacional de Previdência Social (INPS) gastou, no tratamento do acidentado do trabalho, cerca de $70 \%$ de sua verba para toda a assistência médica. Clemente ${ }^{2}$ apresenta resultados animadores desta politica prevencionista.

Análises estatísticas sobre acidentes do trabalho abrangendo universos relativa- mente grandes, são raros aqui no Brasil; Lorena ${ }^{5}$, Ferreira ${ }^{3}$, Mendes ${ }^{7}$ e Nogueiras são alguns poucos pesquisadores que se dedicaram a este assunto. Os dados que serão apresentados referem-se a um programa preventivo que o Grupamento de Acidentes do Trabalho (GAT) do INPS, do então Ministério do Trabalho e Previdência Social, iniciou em 1970.

Como se trata de uma atividade ministerial pouco divulgada, é interessante explicar melhor como se desenvolveu.

Para a execuçāo deste programa foram utilizados médicos e engenheiros selecionados através de concurso de titulos, onde cursos e experiência em segurança e medi-

\footnotetext{
* Do Departamento de Saúde Ambiental da Faculdade de Saúde Pública da USP - Av. Dr. Arnal to, 715 - 01255 - São Paulo, SP - Brasil.

* Do Departamento de Medicina Preventiva da Faculdade de Medicina da USP - Av. Dr. Arnaldo, 455 - 01246 - São Paulo, SP - Brasil.
} 
Nogueira, D. P. et al. Acidentes graves do trabalho na capital do Estado de São Paulo

(Brasil) Rer. Saúde públ., S. Paulo, 15·3-13. 1981.

cina do trabalho eram imprescindiveis. Esses profissionais prestaram serviços, sem vínculo empregaticio, através de credenciamento. Sua função consistia em comparecer às empresas onde havia ocorrido um acidente grave e, após uma entrevista com 0 responsável pela empresa, efetuar um levantamento analítico de riscos no próprio local dos acidentes. Como resultado desta visita, era emitido um relatório minucioso sobre as causas, com indicação de medidas preventivas, assim como das infrações legais. Este relatório elaborado pelo médico ou pelo engenheiro, funcionalmente chamados de técnicos em investigação de acidentes, era submetido an assessor em investigação de acidentes que era também um médico ou engenheiro especializado, mas com maior experiência em infortúnios do trabalho. Após a revisão e correçōes indicadas, o relatório era encamintiado à empresa para execução das medidas preventivas propostas.

Após certo tempo (aproximadamente 2 meses), o assessor comparecia à empresa para verificar o andamento das providências. Caso a empresa se mostrasse recalcitrante no cumprimento das recomendações, o INPS poderia indicar as infrações aos órgãos de fiscalização para fins de autuação. $\mathrm{Na}$ realidade, o programa era essencialmente educativo e somente em última instância é que se recorreria ans órgãos de fiscalização.

A indicação dos acidentes a serem investigados era feita por médicos coordenadores do GAT, que normalmente acompanhavam o tratamento dos acidentados nos hospitais que mantinham convênio com 0 INPS para atendimento dos acidentes de trabalho.

Este programa durou cerca de 5 anos e foi desativado posteriormente por motivos que não são do conhecimento dos autores.

Por ocasião da vigência do programa, acumulou-se uma quantidade apreciável de dados de acidentes de trabalho que se julgou oportuno estudar. O presente trabalho é o resultado deste estudo que pretende apenas mostrar a distribuição proporcional destes acidentes por uma série de variáveis.

\section{MATERIAL E METODOS}

Os dados foram obtidos de processos referentes a 3.930 acidentes de trabalho registrados no INPS ocorridos em São Paulo, Município da Capital, em 1970. Foram considerados apenas os acidentes graves, isto é, aqueles que ocasionaram óbito, incapacidade permanente e incapacidade temporária (casos em que o afastamento do trabalho foi maior do que um mês ou em que as circunstâncias indicaram a oportunidade de uma avaliação face a pressuposição de risco grave), além de casos de doenças profissionais. Foram consultados os seguintes documentos de cada processo:

- comunicação do acidente de trabalho

- registro de acidente grave

- levantamento analítico de risco

- relatório de entrevista inicial

Os dados foram processados através do computador IBM da Universidade de São Paulo.

A população acidentada foi avaliada de acordo com as variáveis: estado civil, faixa etária, sexo e profissão.

Os acidentes foram estudados conforme as seguintes variáveis: tipo, conseqüências, causas, dia da semana e hora em que ocorreu, horas decorridas após o inicio do serviço, agente, número de lesões.

\section{RESULTADOS E COMENTARIOS}

A Tabela 1 foi incluida para fins de caracterização da população estudada, quanto ao estado civil. Cumpre ressaltar que cerca de $40 \%$ dos acidentados eram chefes de familia (casados) com todas as consequiências sociais dai decorrentes. 
NOGUEIRA, D, P. et al, Acidentes graves do trabalho na capital do Estado de São Paulo (Brasil) Rev. Saúde públ., S. Paulo, 15:3-13, 1981.

T A B E L A 1

Distribuição da população em estudo de acordo com o estado civil

\begin{tabular}{l|r|r}
\hline \multicolumn{1}{c|}{ Estado civil } & Número & $\%$ \\
\hline Solteiro & 2237 & 56,9 \\
Casado & 1648 & 41,9 \\
Viúvo & 20 & 0,5 \\
Desquitado & 3 & 0,1 \\
Não referido & 22 & 0,6 \\
\hline Total & 3930 & 100,0 \\
\hline
\end{tabular}

A relação entre os acidentes $e$ a idade pode ser acompanhada pela Tabela 2 . Nota-se que mais de $2 / 3$ dos acidentes graves atingiu trabalhadores com menos de 35 anos de idade, isto é, no periodo de plena capacidade laborativa.

TAB L A 2

Distribuição da população estr dada de acordo com a faixa etária

\begin{tabular}{l|rr}
\hline Idade & Número & $\%$ \\
\hline $14-20$ & 929 & 23,6 \\
$21-25$ & 1036 & 26,4 \\
$26-30$ & 623 & 15,9 \\
$31-35$ & 451 & 11,5 \\
$36-40$ & 300 & 7.6 \\
$41-45$ & 250 & 6,4 \\
$46-50$ & 143 & 3,6 \\
$51-55$ & 88 & 2,2 \\
$56-60$ & 34 & 0,9 \\
60 e mais & 27 & 0,7 \\
Não referido & 49 & 1,2 \\
\hline Total & 3930 & 100,0 \\
\hline
\end{tabular}

Outro aspecto que chama a atenção é 0 percentual de 23,6 para menores de 20 anos. Como estão recém ingressando na força de trabalho, os acidentes que ocorrem nesta faixa são extremamente cruéis, deixando marcas não só físicas mas, principalmente, mentais, fazendo com que muitos destes jovens desenvolvam incompatibilidades, às vezes insanáveis, com o trabalho e a sociedade.

A grande minoria dos acidentados pertencia ao sexo feminino, conforme pode ser visualizado na Tabela 3 .

TA B E L A 3

Distribuição da população estudada de acordo com o sexo

\begin{tabular}{l|r|r}
\hline \multicolumn{1}{r|}{ Sexo } & Número & \multicolumn{1}{c}{$\%$} \\
\hline Masculino & 3554 & 90,5 \\
Feminino & 370 & 9,4 \\
Não referido & 6 & 0,1 \\
\hline Total & 3930 & 100,0 \\
\hline
\end{tabular}

Como a participação da mulher no mercado de trabalho é em torno de $30 \%$, seria de se esperar um percentual maior do que os $9,4 \%$ encontrados. Levando-se em consideração que a mulher atualmente está estendendo seu campo de trabalho para quase todas as ocupações, incluindo as de maior risco de acidentes, os percentuais apresentados parecem confirmar as constatações de Tudor ${ }^{10}$ sobre a tendência que tem a mulher em se acidentar menos que os homens.

A Tabela 4 mostra que a maior parte dos acidentados tinha como profissão "serviços gerais", expressão um tanto vaga que abrange: prático, auxiliar, aprendiz, servente, ajudante, entre outros. Na realidade, trata-se de mão-de-obra não qualificada, quase sempre de iniciantes, ou, em caso contrário, de trabalhadores com baixa escolaridade ou pequeno potencial para progredir em sua profissionalização. Também são usualmente utilizados para substituir colegas mais especializados (no jargão de indústria, são chamados "coringas"). Isto 
NoGUEIRA, D. P. et al. Acidentes graves do trabalho na capital do Estado de São Paulo (Brasil) Rev. Saúde públ., S. Paulo, 15:3-13, 1981.

não quer dizer que os trabalhadores em serviços gerais se acidentem em maior proporção do que os que exercem outras atividades; ocorre que não se encontraram dados confiáveis sobre a distribuição dos trabalhadores em geral, pelas diversas pro- fissões para se poder estabelecer um indice de freqüência. Indica, porém, que cerca de um terço dos acidentados são trabalhadores não qualificados e que as ações preventivas devem levar este fato em consideração na sua programação.

TA B E I A 4

Distribuição da população estudada de acordo com a profissão dos acidentados.

\begin{tabular}{lrc}
\hline \multicolumn{1}{c}{ Profissão } & Número & $\%$ \\
\hline Serviços gerais & 1226 & 31,2 \\
Prensista em geral & 647 & 16,5 \\
Maquinista em geral & 166 & 4,2 \\
Mecânica em geral & 156 & 4,0 \\
Marceneiro em geral & 133 & 3.4 \\
Torneiro & 124 & 3,2 \\
Carpinteiro em construção e mobiliálio & 87 & 2.2 \\
Tecelăo & 66 & 1,7 \\
Impressor & 59 & 1,5 \\
Montador em geral & 54 & 1,4 \\
Contramestre & 52 & 1,3 \\
Serralheiro & 49 & 1,2 \\
Ajustador mecánico & 45 & 1,1 \\
Estampador & 44 & 1,1 \\
Polidor & 44 & 1,1 \\
Outras profissões & 978 & 24,9 \\
\hline Total & 3930 & 100,0 \\
\hline
\end{tabular}

$\mathrm{Na}$ Tabela 5 estão distribuídos os acidentes conforme o tipo. Por acidente tipo entende-se aquele que decorrer pelo exercício do trabalho, a serviço da empresa, provocando lesão corporal, perturbação funcional ou doença que cause a morte ou a perda ou redução, permanente ou temporária, da capacidade para o trabalho. Doenças do trabalho são as chamadas doenças profissionais, inerentes a determinados ramos de atividade e relacionados em ato do então Ministro do Trabalho e Previdência Social. São, ainda, incluidas as doenças não degenerativas nem inerentes a grupos etários, resultantes das condiçōes especiais ou excepcionais em que o trabalho seja executado e que causam redução permanente para o trabalho. Acidentes de trajeto são os sofridos pelo empregado, ainda que fora do local e horário de trabalho, no percurso da residência para 0 trabalho ou deste para aquele.

$\mathrm{Na}$ referida tabela chama a atenção o número insignificante de acidentes de trajeto, o que se explica porque tais acidentes praticamente foram excluidos do programa pelas dificuldades de investigação. 
NOGUEIRA, D. P. et al. Acidentes graves do trabalho na capital do Estado de São Paulo (Brasil) Rev. Saúde publ., S. Paulo, 15:3-13, 1981.

\section{T A B E L A 5}

Distribuição da população em estudo conforme o tipo de acidente

\begin{tabular}{lr|r}
\hline \multicolumn{1}{c}{ Tipo } & Número & $\%$ \\
\hline Acidente tipo & 3242 & 82,4 \\
Doença do trabalho & 20 & 0.6 \\
Acidente do trajeto & 3 & 0,1 \\
Não referido & 665 & 16,9 \\
\hline Total & 3930 & 100,0 \\
\hline
\end{tabular}

Mendes ${ }^{7}$ encontrou os seguintes resultados percentuais:

$$
\begin{aligned}
& \text { - acidente tipo } \\
& \text { - doença do trabalho } \\
& \text { - acidente do trajeto } \\
& \text { - sem informações } \\
& \text { Total }
\end{aligned}
$$

É bem razoável supor que a grande maioria dos acidentes incluídos na classe "não referidos" sejam acidentes tipo. Levando-se isto em consideraçāo, os resultados dos dois trabalhos se aproximam hastante.
Um aspecto que chama a atenção nos dois resultados é o número extremamente reduzido de doenças profissionais. Este número pode indicar que não se está fazendo o diagnóstico correto das doenças profissionais, ou tais enfermidades não estão sendo comunicadas como tal. Com a formação de grande número de especialistas em medicina do trabalho supõe-se que o diagnóstico das doenças do trabalho seja feito com mais facilidade. No entanto, a falta de comunicação só será sanada quando houver uma modificação na perícia médica do Instituto Nacional de Previdência Social (INPS) de tal forma que todos os beneficios concedidos por doenças, eventualmente relacionáveis com o trabalho, forem analisados quanto a esta possibilidade e, caso o nexo seja estabelecido, enquadrados como doença profissional.

A Tabela 6 mostra as conseqüências destes acidentes, entendendo-se por incapacidade temporária a perda total da capacidade para o trabalho, por um período limitado de tempo, impossibilitando o acidentado, na opinião do médico, de voltar à sua ocupação habitual no dia imediato ao do acidente, dentro do horário regulamentar. Incapacidade permanente é a redução, em caráter permanente, parcial ou total, da capacidade para o trabalho.

TA B E L A 6

Distribuição da população em estudo conforme a consequeencia dos acidentes.

\begin{tabular}{lcc}
\hline \multicolumn{1}{c|}{ Consequência } & Número & $\%$ \\
\hline Incapacidade temporária & 1417 & 36,1 \\
Incapacidade permanente & 1838 & 46,7 \\
Morte & 10 & 0,3 \\
Não referido & 665 & 16,9 \\
\hline Total & 3930 & 100,0 \\
\hline
\end{tabular}


NOGUEIRA, D. P. et al. Acidentes graves do trabalho na capital do Estado de São Paulo

(Brasil) Rer. Saude públ., S. Paulo, 15/3-13. 1981

Para fins de comparação, os percentuais encontrados por Mendes : e Ferreira 3 foram:

\begin{tabular}{l|r|r|} 
& Mendes 7 & Ferreira 3 \\
\hline Incapacidade temporária & 43,1 & 28,7 \\
Incapacidade permanente & 56,9 & 71,3 \\
Total & 100,0 & 100,0 \\
\hline
\end{tabular}

A incapacidade permanente sempre indica que $o$ acidente que a originou foi de grande gravidade. Analisando os resultados dos três estudos, verifica-se que o percentual de acidentes que ocasionaram incapacidade permanente foi mais elevado nos acidentes provenientes das pequenas empresas no estudo de Mendes i e mais elevado ainda entre os prensistas, como contatou Ferreira : Uma explicação para os $56,9 \%$ de incapacitados permanentes em conseqüência de acidentes ocorridos nas pequenas empresas, são suas condições precárias de segurança e medicina do trabalho, além de problemas com a assistência médica aos acidentados tais como: demoras no atendimento de emergência, agravamento de lesões por tratamento caseiro, permanência no trabalho apesar da lesão, retorno ao trabalho precocemente, entre outros.

A Tabela 7 mostra os vários fatores que ocasionaram os acidentes. A freqüência modal recaiu no trabalho com prensas. Quase sempre os acidentes em prensas são de natureza grave incluindo, na maioria das vezes, perdas anatômicas importantes. Nảo $\dot{e}$ de se admirar que o maior contingente dos acidentes graves seja ocasionado por prensas. Ferreira ", que estudou minuciosamente os acidentes com prensas, recomenda atenção especial para as prensas mecânicas excêntricas, advertindo ainda que o maior risco envolve as operaçōes em prensas com sistema de alimentação manual, comando tipo pedal e estampos tipo aberto.
A distribuição dos acidentes pelos dias da semana pode ser vista através da Tahela 8 . O número maior de acidentes ocorre nas segundas-feiras. Os demais dias úteis praticamente se igualam sendo que domingo, como seria de esperar, é o dia em que ocorre o menor número de acidentes graves. Ferreira : também encontrou 19\% de acidentes da sua população ocorrendo nas segundas-feiras. Excessos de fim de semana e retomada da plena atividade ao fim de um descanso poderiam participar do mecanismo desta alta incidência na segunda-feira. Outro ponto a ponderar seriam os acidentes esportivos que eventualmente possam estar sendo considerados como acidentes de trabalho.

A Fig. I mostra a distribuição dos acidentes conforme a hora da sua ocorrência. Verifica-se que a partir das $6: 30 \mathrm{~h}$ há um grande aumento até às 10:00 h, quando começa a cair, para crescer novamente a partir das 12:00 h até às 16:00 h, quando decresce pela segunda vez. É difícil uma explicação para esta distribuição, uma vez que não se teve elementos para cálculo de coeficientes no lugar de percentuais. Entretanto, alguns comentários podem ser feitos, embora mais especulativos e baseados na experiência de autores deste artigo, na qualidade de médicos do trabalho em empresas industriais do que propriamente como conclusão a partir dos dados percentuais. A incisura no meio do gráfico deve coincidir com o horário do almoço. Talvez o pico matutino esteja relacionado 
NOGUEIRA, D. P. et al. Acidentes graves do trabalho na capital do Estado de São Paulo (Brasil) Rev. Saúde puibl., S. Paulo, 15:3-13, 1981.

TA B E L A 7

Distribuição da população estudada de acordo com os fatores que ocasionaram os acidentes.

\begin{tabular}{|c|c|c|}
\hline Fatores dos Acidentes de Trabalho & Número & $\%$ \\
\hline - Trabalho em prensas de qualquer tipo & 999 & 25.5 \\
\hline - Trabalho em máquinas para metais & 751 & 19.1 \\
\hline - Trabalho em outras máquinas & 581 & 14.8 \\
\hline - Trabalho em máquinas para madeiras & 463 & 11.8 \\
\hline $\begin{array}{l}\text { - Limpando, lubrificando. ajustando ou reparando } \\
\text { máquinas }\end{array}$ & 283 & 7,2 \\
\hline $\begin{array}{l}\text { - Transportando. levando ou abaixando materiais } \\
\text { e objetos }\end{array}$ & 228 & 5,8 \\
\hline - Trabalho em máquinas para plástico & 159 & 4,0 \\
\hline - Trabalho em guilhotina & 88 & 2,2 \\
\hline - Trabalho em máquinas tipográficas & 86 & 2,2 \\
\hline - Outras causas & 58 & 1,5 \\
\hline $\begin{array}{l}\text { - Acidentes e atropelamentos por carrinhos de } \\
\text { qualquer tipo }\end{array}$ & 56 & 1,4 \\
\hline $\begin{array}{l}\text { - Trabalhando com ferramentas, exceto tesouras. } \\
\text { canivetes, etc. }\end{array}$ & 35 & 0,9 \\
\hline $\begin{array}{l}\text { - Escorregando. tropeçando ou pisando materiais e } \\
\text { objetos }\end{array}$ & 33 & 0.8 \\
\hline - Acidentes com escadas fixas ou manuais & 26 & 0.7 \\
\hline $\begin{array}{l}\text { - Dermatites de contato, intoxicaçōes ou } \\
\text { envenenamento }\end{array}$ & 23 & 0,6 \\
\hline $\begin{array}{l}\text { Manuseando materiais e objetos (ferimentos e } \\
\text { contusóes causados por lascas, arestas, pregos, etc., } \\
\text { existentes nesses materiais) }\end{array}$ & 18 & 0,5 \\
\hline $\begin{array}{l}\text { - Ferimentos causados por tesouras, giletes, } \\
\text { canivetes, etc. }\end{array}$ & 17 & 0,4 \\
\hline - Corpo estranho nos olhos & 16 & 0,4 \\
\hline $\begin{array}{l}\text { - Quelmaduras leves por água, vapores ou outros } \\
\text { materiais quentes }\end{array}$ & 3 & 0,1 \\
\hline - Ignorado & 7 & 0,1 \\
\hline Total & 3930 & 100,0 \\
\hline
\end{tabular}

com a incoordenação psicomotora ocasionada pela fome sabendo-se que a refeição matinal dos trabalhadores é sabidamente deficiente ou simplesmente não existe. $O$ pico vespertino também poderia ser explicado pelo mesmo motivo, mas agravados pelo açodamento usual de fim de jornada.
O gráfico apresentado na Fig. 2, também pode servir para algumas especulaçōes sobre o horário. Nele observa-se que o maior número de acidentes graves ocorrem na primeira hora de trabalho. Esta incidência elevada possivelmente está relacionada com o periodo de adaptação fisioló- 
NoGUeIRA, D. P. et al. Acidentes graves do trabalho na capital do Estado de São Paulo (Brasil) Rer. Saude públ, S. Paulo, 15:3-13, 1981.

TA B E L A 8

Distribuição da população em estudo de acordo com o dia da semana

\begin{tabular}{lcc}
\hline \multicolumn{1}{c}{ Dia da Semana } & Número & $\%$ \\
\hline Segunda-feira & 768 & 19.6 \\
Terça-feira & 707 & 18.0 \\
Quarta-feira & 681 & 17,3 \\
Quinta-feira & 689 & 17.5 \\
Sexta-feira & 702 & 17,9 \\
Sábado & 312 & 7.9 \\
Domingo & 68 & 1.7 \\
Não referido & 3 & 0.1 \\
\hline Iutal & 3930 & 100.0 \\
\hline
\end{tabular}

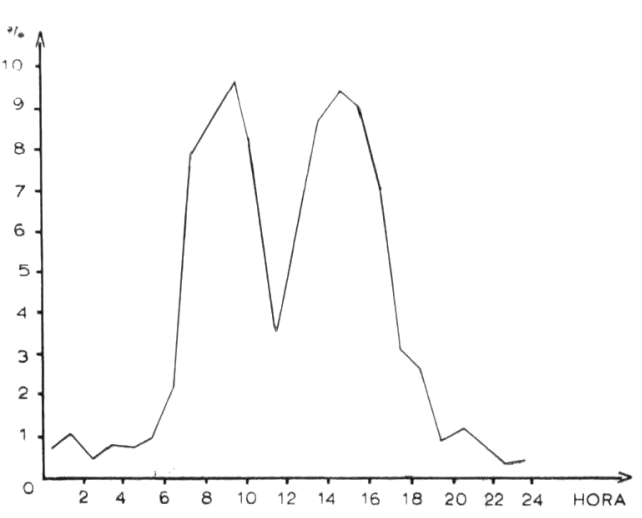

Fig. 1. Distribuição percentual dos acidentes conforme a hora ro dia.

grica ("aquecimento") que tem lugar no organismo quando inicia uma jornada de trabalho ou esporte. Após esta primeira hora há um decréscimo paulatino até que tenham transcorrido $4: 00$ hs de trabalho; esta incisura também deve estar relacionada com a pausa para o almoço. Há, também, uma elevação de incidência nas duas últimas horas de expediente usual de 8:00 h que possivelmente está relacionada com problemas de fadiga. Cumpre, ainda, assinalar que 166 acidentes ocorreram após $9: 00 \mathrm{~h}$ de trabalho dos quais 35 após 12:00 h. Certamente tais jornadas são desaconselháveis pois criam situaçōes francamente favoráveis à ocorrência de acidentes do trabalho. $\mathrm{Na}$ realidade, a instituição de sistemas de horas extras en muitas empresas se torna permanente. Nestas empresas não é incomum os trabalhadores cumprirem jornadas de 14 e até 16 horas diárias incluindo, às vezes, até 0 domingo. Certamente seria estranhável a não ocorrência de acidentes nestas empresas.

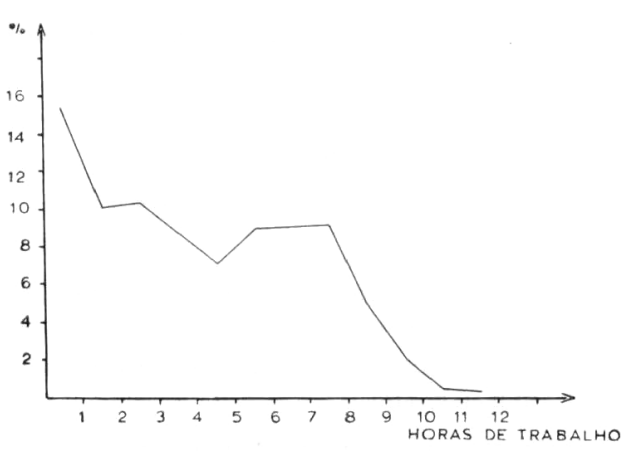

Fig. 2 - Distribuição percentual dos acidentes conforme o número de horas decorridas após o início do serviço.

A Tabela 9 mostra que a proporção de acidentes graves, causados por atos inseguros, não é tão elevada, contrariando os dados clássicos de Heinrich + que atribuiu aos atos inseguros $88 \%$ dos acidentes do trabalho. Mange; encontrou 78,6\%, enquanto no presente trabalho a proporçāo encontrada foi de apenas $22,5 \%$, praticamente igual à encontrada por Ferreira" $(22,6 \%)$.

Os atos inseguros são as causas de acidentes do trabalho que residem exclusivamente no fator humano, isto é, aqueles decorrentes da execução de tarefas de uma forma contrária às normas de segurança.

Condições inseguras são as causas dos acidentes do trabalho que decorrem diretamente das condiçóes do Iocal ou do ambiente de trabalho. Estas condiçōes inseguras de local ou de ambiente são conhecidas também como riscos profissionais. 
NOGUEIRA, D. P. et al. Acidentes graves do trabalho na capital do Estado de São Paulo (Brasil) Rev. Saúde públ., S. Paulo, 15:3-13, 1981.

T A B E L A 9

Distribuição da população estudada conforme a causa dos acidentes.

\begin{tabular}{l|c|c}
\hline \multicolumn{1}{c|}{ Acidente Segundo a Causa } & Nủmero & $\%$ \\
\hline - Condição insegura & 1561 & 39,7 \\
- Ato inseguro & 883 & 22,5 \\
- Ambos & 1431 & 36,4 \\
- Não referido & 55 & 1,4 \\
\hline Total & 3930 & 100,0
\end{tabular}

Nos acidentes ocorridos apenas en prensas, Ferreira ${ }^{3}$ verificou que só $10 \%$ dos acidentes foram causados por exclusivamente atos inseguros.

Quando um acidente é analisado de forma criteriosa, as condições inseguras tendem a aparecer com muito maior freqüència do que em investigações sumárias ou, o que é pior, tendenciosas. A "negligência do empregado" é uma causa de acidente muito simplista mas ainda muito utilizada, pois é mais facilmente aceita pelas chefias do que admitir unı condição insegura da máquina. Esta posição "tipo avestruz" do profissional, não irá prevenir os acidentes futuros pois a causa real não foi eliminada, mas infelizmente ainda é comum encontrar tais "conclusóes de investigação".

$\mathrm{Na}$ Tabela 10 nota-se que a maioria dos acidentados sofreu apenas uma lesão embora também chame a atenção que quase un terço apresentou duas ou mais lesões.

T A B E L A 10

Distribuição da população em estudo conforme o número de lesões apresentadas

\begin{tabular}{crc}
\hline Número de Lesões & Número & \multicolumn{1}{c}{$\%$} \\
\hline 1 & 2765 & 70,4 \\
2 & 1064 & 27,1 \\
3 & 99 & 2,5 \\
Não referido & 2 & 0,0 \\
\hline Total & 3930 & 100,0 \\
\hline
\end{tabular}

Analisando-se retrospectivamente a filosofia que norteia a prevenção de acidentes no Brasil, verifica-se que de 1970 a 1975 o então INPS, através do seu GAT, tinha especial preocupação com os aspectos preventivos da infortunística laborativa; assim, toda a investigação de acidente tinha por objetivo final a adoção de medida de prevençāo.

Quando o Ministério do Trabalho assumiu o encargo de zelar pela prevençăo de acidentes, a sistemática adotada foi de outra natureza. Assim, as atividades prevencionistas passaram a ser executadas principalmente pelos profissionais de Medicina do Trabalho e de Segurança do Trabalho existentes nas empresas, em face da obrigatoriedade destas organizarem seus próprios Serviços Especializados de Segurança e Medicina do Trabalho. Essa nova sistemática indubitavelmente deu resultados, uma vez que as estatísticas oficiais vêm mostrando, nos últimos anos, redução da taxa de freqüência de acidentes.

No entanto, é de se lamentar que tenha sido abandonado o sistema utilizado pelo então INPS, pois as duas sistemáticas poderiam perfeitamente coexistir; assim, através de um trabalho entrosado do Ministério do Trabalho e do Ministério da Previdência Social, poder-se-ia levar adiante uma atividade preventiva eficiente, com a vantagem de acumular-se dados estatísticos sobre acidentes de trabalho de grande importância para investigações epidemiológicas futuras. 
Nogueira, D. P. et al. Acidentes graves do trabalho na capital do Estado de São Paulo (Brasil) Rer. Saude pübl., S Paulo, 15:3-13. 1981

Ao desativarem-se as investigaçies feltas a partir de acidentes graves, perdeu-se uma excelente oportunidade para se fazer a educação preventiva tanto de empregadores como de empregados. Além disso, não obstante o INPS não ter funçào fiscalizadora, o retorno do assessor às empresas onde ocorreram acidentes constituia uma importante atividade prevencionista, uma vez que estara sempre presente a possibilidade de ser feita a denúncia an Ministério do Trabalho no caso das medidas recomendadas năo terem sido adotadas.

Tomando-se apenas os casos estudados no presente trabalho, corresponderam eles a 3.930 visitas feitas por un técnico a tmpresas onde tinham ocorrido acidentes graves e outras tantas recomendaçóes preventivas eficientes, que certamente foram de grande utilidade para evitar a repetição de acidentes semelhantes.

Seria, pois, de grande vantagen para os trabalhadores, para as empresas e para " Pais, que voltassem a ser realizadas as investigações sobre acidentes pelo INPS que, como segurador que é dos infortunios laborativos, tem interesse direto pela sua prevençāo adequada.

\section{CONCLUSOES}

Com base nos resultados referentes ao universo da pesquisa, justificam-se as seguintes conclusões:

1. (Quase a metade $(46.7 \%)$ dos acidentes graves ocasionaram incapacidade permanente.

2. A maior parte dos acidente ocorrell em trabalhos com prensas $(25,5 \%)$.

3. Não há grande diferença quanto ao dia útil enr que ocorreu o acidente embora a incidência seja levemente maior às segundas-feiras.

4. O maior numero de acidentes matutinos ocorreu entre as 8 e $10 \mathrm{~h}$ e os vespertinos entre às 14 e $16 \mathrm{~h}$.

5 O maior número de acidentes ocorreu na primeira hora do turno de trabalho.

60 ato inseguro como causa isolada foi responsável por $22,5 \%$ dos acidentes.

7 Em 29.6\% dos eventos ocorreram duas ou mais lesress.

NoGutiRA, D. P. et al. [Serious on-the-job accidents in thr City of $s$ Paulo, Brazi]]

Rer. Saúde públ., S. Paulo, 15:3-13, 19:1.

ABSTRACT: In 1970, the Accidents On-the-Job Group of the National Institute of Social Security (INPS), began a special program for the prevention of on-the-job-accidents. The following factors were studied in 3,930 cases: age, sex, marital status, occupation, cause of accident, date of occurrence, time of occurrence, occurred how soon after beginning day's work, number and type of body lesions, Jimitation of working capacity.

UNITERMS: Accidents, industrial, São Paulo, SP, Brazil. Accidents, prevention. 
NoguerRA, D. P. et al. Acidentes graves do trabalho na capital do Estado de São Paulo (Brasil) Rev. Saúde pübl., S. Paulo, 15:3-13. 1981.

\section{REFERENCIAS BIBLIOGRAFICAS}

1. AMARO, J. M. Conceitos e definições básicas. In: Curso de supervisores de segurança do trabalho. São Paulo, Ministério do Trabalho/FUNDACENTRO. s.d.

2. CLEMENTE, D. S. Análise das estatisticas de acidentes de trabalho. Bot. estat. FUNDACENTRO, 4:2-10, 1978.

3. FERREIRA. L. L. Influencia do fator humano nos acidentes de trabalho. São Paulo. Faculdade de Saúde Pública da USP, 1975.

4. HEINRICH, H. V. Industrial accident prevention. New York. McGraw Hill. 1941.

5. LORENA, C. Prevenção de acidentes do trabalho no meio rural. In: Congresso Nacional de Prevenção de Acidentes do Trabalho, 16 ${ }^{\circ}$, Porto Alegre, 1977. Anais. São Paulo, FUNDACENTRO, 1977, p. 50-7.

6. MANGE, R. Prevençāo de acidentes na estiva. Rio de Janeiro. Instituto de
Aposentadoria e Pensōes da Estiva, 1940. (APE Publ., 7).

7. MENDES. R. Importancia das pequenas empresas industriais no problema de acidentes de trabalho em São Paulo. São Paulo, 1975. [Dissertação de Mestrado - Faculdade de Saúde Pública da USP].

8. NOGUEIRA, D. $P, O$ fator humano na gênese dos acidentes do trabalho. Rer. paul. Med., 43:138-44, 1953.

9. SAAD, E. G. Legislasão de adidentes de segurança, higiene e medicina do trabalho. 5" ed. São Paulo. Mínistério do Trabalho/FUNDACENTRO. 1977.

10. TUDOR. T. C. Problemas relativos ao trabalho na comparação do homem com a mulher. Diálogo méd., 3(2):21-4, 1977.

Recebido para publicação em 26/02/1980 Aprovado para publicacão em 13/10/1980 